$\xi_{p}$

\title{
Preliminary Study on Youth Lifestyle with Regards to Energy Saving
}

\author{
Nur Shakirah Md Salleh ${ }^{1} *$ \\ ${ }^{1}$ Department of Systems and Networking, University Tenaga Nasional, Malaysia \\ *Corresponding author E-mail: shakirah@uniten.edu.my
}

\begin{abstract}
The advancement of information and communication technology (ICT) leads the increasing number of digital devices. The paper focuses on a preliminary study in discovering the youth lifestyle including electricity usage and preferred electricity appliances towards energy saving. This research carried out one of the data gathering techniques; survey, to find the level of the youth lifestyle towards energy saving among youth in a higher level-learning institute. This paper shares the processes and algorithm in finding the result of this type of study. The results derived from the algorithm show that $67.15 \%$ of the respondents are implementing energy saving in their lifestyle. This lifestyle partially influences their preferences in choosing electrical appliances with $78.74 \%$ of the respondents are looking forward to energy saving products that comes with a known brand and affordable price.
\end{abstract}

Keywords: Energy, Youth, Social Science

\section{Introduction}

Malaysia is heading towards developed county status. Due to the increasing number of developed area and new township, the electricity consumption increased. The advancement of information and communication technology (ICT) leads the growing number of gadgets such as mobile phone, computer. Malaysian spent 14 hours a day on digital devices which $87 \%$ of them browse the internet [1].

Since the year 2008, Tenaga Nasional Berhad (TNB) and other government bodies are enormously promoting Energy Efficiency Campaign [2]. Consumers of domestic, commercial and industry need to realize the importance of energy efficiency and play their role and responsibility together with the government [2]. The similar concern happened in United States of America (US). In 1978, they started to consider the energy issues that affect the government for business and commerce [3]. The solutions to these problems depend on the knowledge and attitudes of an informed community [3].

According to the 1997 National Youth Development Policy, the age range of youth is between 18 to 40 years old [4]. In the next decades, the earlier age of youth will be the main consumer in energy usage, especially in the commercial and residential area. Youth lifestyle is very important in realizing the nation's vision of green technology. If the lifestyle can be nurtured from the beginning, the energy saving lifestyle will become a culture in society.

The remainder of this paper is organized as follows: Section provides an overview of energy efficiency and youth lifestyle. Section 3 describes the methodology of data gathering, and Section 4 describes the survey analysis and results. Finally, a conclusion is made.

\section{Overview}

ICT helps in improving the quality of human capital by accelerating the economy to grow [5]. In moving together with the modernization, more than $98 \%$ of residential units in Malaysia are now supplied with electricity [6]. Most of them are majorly equipped with household appliances that use electricity consumption such as fan, air conditioner, washing machine, and television [7]. With the growth of ICT, most of the individual in Malaysia has access to the digital devices such as mobile phone and computer. Malaysian spent 14 hours a day on digital devices which $87 \%$ of them browse the internet [1]. More time spent on gadgets increase the frequency on charging them. In 2017, among the popular Internet activities carried out by the Internet user were participating in social networks (86.3\%), downloading images, films, video or music; playing or downloading games $(81.2 \%)$, getting information about goods and services $(80.4 \%)$, downloading software or applications $(74.5 \%)$ and sending or receiving e-mails $(70.4 \%)$ [8].

The high demand for this source of energy makes a high impact on human life as well as the environment in a negative way. The side effect of it can be seen from the climate change, air and water pollution, and other environmental impacts [9]. In controlling this impact, the National Assessment of Education Progress (NAEP) has conducted a national assessment of energy awareness among young adults (ages 26 to 35) [3]. This study covers various types of energy including oil and electricity. One (1) of the areas asked in the energy assessment is about energy conservation. Generally, most of the respondents are familiar with some practical conservation techniques that reduce energy transportation and energyrelated terminology however not in the broader issue such as energy reserves [3].

Due to this negative impact, the Malaysian government took some actions to encourage the people to use fewer energy sources. The 
huge energy provider in Malaysia, TNB together with several government bodies such as the Energy Commission have done a lot of initiatives and campaigns to encourage the consumer to use energy efficient electrical appliances. This includes a higher tariff for higher electricity usage, online media advertisement, and introducing Energy Label scheme on electrical appliances [10].

\subsection{Energy Efficiency}

Energy efficiency (EE) helps in sustainability due to increasing demand for energy usage. EE helps in reducing the operational cost at the same time reducing the carbon emission [10]. Other than basic electrical appliances such as fan, air conditioner, fridge and washing machine, the electronic devices such as the computer, smartphone, and smartwatch are majority youth's gadgets [10]. The appliances identified as EE by referring to the Start Rating on the Energy Label.

An earlier study made in 2015 whereby the purpose of the study is to identify the awareness of energy saving. In this study, the result shows the majority of the respondents are unaware of energy saving [11].

\subsection{Youth}

According to the 1997 National Youth Development Policy, the age range of youth is between 18 to 40 years old [5]. However, the policy also specifies that youth development programs and activities shall be focused on youth ages 18 to 25 [5]. Youth may influence the nation's future such as in economy, politics, and energy. In the next decades, the earlier age of youth will be the main consumer in energy usage, especially in the commercial and residential area.

Youth lifestyle is very important in realizing the nation's vision of green technology. This is because they are the key factor of future energy consumption. If the lifestyle can be nurtured from the beginning, the energy saving lifestyle will become a culture in society. The consumption of energy by electrical appliances took just a bite out of monthly utility commitment. This commitment is not affecting the organization and business areas only but also affecting university students' financial commitment since they need to pay for utility bill no matter they stay on-campus or off-campus [12].

\section{Methodologies}

A preliminary survey by youth was undertaken in July 2018. Design of the questionnaire was inspired by some prior literature on the energy saving done by TNB and Energy Commission. This section describes the components of data collection and analysis.

\subsection{Designing Survey Questions}

The selected data gathering method is quantitative research [13]. This methodology helps in collecting input from a huge number of respondents. The purpose of the survey is to explore the lifestyle of youth that may relate to energy saving habits. The questionnaires constructed as closed-ended questions. This question type was chosen because it is ideal for calculating statistical and percentage, as the answer set is identified.

The questionnaires are presented in Likert scale form. The frequency is measured based on each question asked. Likert scale captures responses in scale form. This method helps in to assess the respondents' frequency of lifestyle toward the questions.

The questionnaire covers electricity consumer demographics, their habits in electricity usage and some preferences in choosing the electrical appliances. Most of them are electric consumers and paying their own electricity bill.

The questions are divided into two (2) parts, Electricity Usage (EU) and Preferred Electrical Appliances (EA). EU consists of nine (9) questions. This captures the respondents' habits toward basic electricity usage. EA consists of three (3) questions. The questions constructed to identify some the potential consumer preferences in choosing electrical appliances. All of these questions apply Likert scale with the level of occurrences or preferences are from one (1) to five (5) [14]. Scale one (1) indicates never and five (5) indicates always [14].

\subsection{Respondents}

Respondents are the people whom the researcher selects as samples for their study [15]. The respondents usually respond to questionnaires in quantitative research. They usually respond in general answer [15].

Sampling is a method that allows researchers to conclude information about a population, without having to investigate every individual $[16,17]$. This research implements Stratified Random Sampling method in selecting the samples. The sample selected from various education level and colleges as sub-populations [18]. It is expected to vary measurement of interest among the different sub-population [19]. The targeted respondents are the youth of age between 18 to 25 years old. In Malaysia, youth in this age range usually found in foundation, diploma, and bachelor degree level. The sample of this preliminary survey consists of 120 university students from different colleges and education level in a private university.

All respondents completed the questionnaire individually. They are given 5 to 10 minutes in answering the survey questions.

\subsection{The Process of Information Gathering}

Information gathering helps in supporting the results. It is important to have a clear objective, correct respondents' demographics, and a suitable data-gathering medium. A series of data gathering processes done and described as follows.

Process 1: Preparation of Questionnaire

1 Start

2 Draft questionnaires

3 Run pilot test on a small third-party group

4 While there is correction or unclear question

4.1 Correct the questions based on the feedback

4.2 Run pilot test on a small third-party group

5 Finalize the questions

6 End

Process 2: Distribution of Questionnaire

1 Start

2 Identify the group of respondents

3 Distribute survey in hardcopy form

4 Collect responses

5 Screen responses

6 If the response is partial or void

7 Then discard response from the list

8 End

The outcome of these processes is gathering responses. In assuring the data validity, the responses are thoroughly filtered. Any incomplete form will be excluded from the counting process.

\subsection{The Process of Data Analysis}

In generating the summary of responses, an online tool is used. Google form is the tool used in this phase. The process of generating the summary of data analysis describes in the following process.

Process 3: Generate Response Summary

1 Start

2 Enter filtered offline responses into the online form

3 Generate summaries of responses

4 End

The output of Process 3 is the input for Process 4. Process 4 shows the process of finding the mean level of occurrences or prefer- 
ences. The result is further focusing on finding the percentage of the respondent who is really adapting to the culture of energy saving in their daily life.

Process 4: Data Analysis for Electricity Usage (EU) and Preferred Electrical Appliances (EA)

1 Start

2 Count the weight of response by multiplying the total respondents with its respective scale of each question

3 Find mean of each question by adding all results in Process 4.2 and then divide by the total number of respondent

4 Get the level of occurrence by calculating the percentage of the mean of each question respective to the scale range.

5 Find the average mean from the sum of all mean in Process 4.2 then divide with the number of questions

6 Filter the positive habit (scale 4 and 5) in each category. Get the percentage of it 10 End

\section{Data Analysis and Results}

This section shows a list of equations implemented in generating the result.

\subsection{Data Analysis}

Mean and percentage are the metrics used in the data analysis. The total number of the filtered respondent is label as R. Process 4 describes the method in analyzing the data from the mean value. By implementing the Process 4.2, the total respondents, $\mathrm{T}$ of each scale of each question counted. $\mathrm{T}$ is used in Equation 1 to get the mean of overall responses to each question, $\mathrm{M}_{\text {scaleRN. }} \mathrm{N}$ represents the question number.

$\mathrm{M}_{\text {scaleRN }}=\left(\left(\mathrm{T}_{1 \mathrm{RN}} \times 1\right)+\left(\mathrm{T}_{2 \mathrm{RN}} \times 2\right)+\left(\mathrm{T}_{3 \mathrm{RN}} \times 3\right)+\left(\mathrm{T}_{4 \mathrm{RN}} \times 4\right)+\right.$

$\left.\left(\mathrm{T}_{5 \mathrm{RN}} \times 5\right)\right) \div \mathrm{R}$

The percentage of the mean from Equation 1 derives in Equation 2 The division of five (5) used in this equation represents the range of level of occurrence or preferences from 1 to 5 .

$\mathrm{PM}_{\text {scaleRN }}=\left(\mathrm{M}_{\text {scaleRN }} \div 5\right) \times 100$

Process 4.5 implements in Equation 3. This equation used in computing the mean of the overall lifestyle of EU and EA. The division of $\mathrm{N}$ is a variable used to represent the number of the statement.

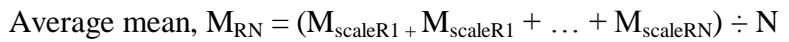

In measuring the overall lifestyle of EU, the value of $\mathrm{N}$ is nine (9) while in EA, the value of $\mathrm{N}$ is three (3).

In measuring the habit in Electricity Usage (EU) and Preferred Electrical Appliances (EA) among the respondents, only scale four (4), and five (5) counted.

$\mathrm{P}_{\mathrm{EU}}=\left(\mathrm{T}_{4 \mathrm{RN}}+\mathrm{T}_{5 \mathrm{RN}}\right) \div \mathrm{R} \times 100$

Equation 4 produces the percentage of respondents whose most of the time concern about energy saving in EU and EA as described in Process 4.6

\subsection{Results}

Based on the application of Process 1, the set of questionnaire revised three (3) times. The Process 2 and Process 3 executed on the same day. The screening process concludes Process 2 with results of 20 void responses gathered. Process 3 converts the offline response into an online form, and then it produces the summary of responses. This output helps in the process of analyzing the responses. Process 4 helps to measure the survey results.
As seen in Table 1 and Table 2, there are two (2) types of results shown on both tables. $\mathrm{M}_{\text {scaleRN }}$ shows the mean of overall responses to each question, while the percentage of $\mathrm{P}_{\mathrm{EU}}$ indicates the habit in EU and EA as described in 4.1.

Table 1: Survey Results of Occurrences Energy Saving Lifestyle in EU

\begin{tabular}{|c|c|c|}
\hline \multirow{2}{*}{ Lifestyle (EU) } & \multicolumn{2}{|c|}{ Results } \\
\cline { 2 - 3 } & $\mathrm{M}_{\text {scaleRN }}$ & $\mathrm{P}_{\mathrm{EU}, \%}$ \\
\hline Turn off the fan when no one is in the room & 4.45 & 85.51 \\
\hline $\begin{array}{c}\text { Turn off the air conditioner when no one is in the } \\
\text { room }\end{array}$ & 4.42 & 86.96 \\
\hline Turn off the TV when no one is watching it & 4.20 & 78.26 \\
\hline $\begin{array}{c}\text { Set the air- conditioner temperature to be in be- } \\
\text { tween 23-25 Celsius }\end{array}$ & 3.09 & 40.58 \\
\hline Clean the air- conditioner filter & 2.93 & 30.43 \\
\hline $\begin{array}{c}\text { Close the window when the air- conditioner is } \\
\text { operating }\end{array}$ & 4.61 & 91.30 \\
\hline Keep fridge organized & 3.80 & 60.87 \\
\hline Switch off computer & 3.68 & 56.52 \\
\hline Full load washing machine & 4.01 & 73.91 \\
\hline Average, $M_{\mathrm{RN}}$ & 3.91 & 67.15 \\
\hline
\end{tabular}

The average of EU lifestyle among youth is nearly 4.00. This result is in between high and average possibility of occurrences energy saving in youth lifestyle. Clean the air conditioner filter results in the lowest occurrences. This response may result from the potential of this activity to occur is once or twice per year. Hiring the air conditioner service provider can also do this job.

However, as a possible daily usage, $91.30 \%$ of respondents close the window when the air conditioner is operating. This result is a good sign that the respondents are aware that more energy requires to cool down the temperature of the room when the window is open while the air conditioner is operating. From this result, nearly $70 \%$ of respondents concerned about the energy saving by controlling the electricity usage. However, the awareness of using the air conditioner in a better way can be improved. This result is probably due to hot weather in Malaysia that influence them to use the air conditioner beyond the recommended degree for energy saving.

Table 2: Survey Results of Preferences in Choosing Electrical Appliances

\begin{tabular}{|c|c|c|}
\hline \multirow{2}{*}{ Lifestyle (EA) } & \multicolumn{2}{|c|}{ Results } \\
\cline { 2 - 3 } & $\mathrm{M}_{\text {scaleRN }}$ & $\mathrm{P}_{\mathrm{EU}, \%}$ \\
\hline Brand influence the choice & 4.14 & 81.16 \\
\hline Price of the product influence the purchase & 4.04 & 73.91 \\
\hline Energy saving star rating influence the choice & 4.23 & 81.16 \\
\hline Average, $\mathrm{M}_{\mathrm{RN}}$ & 4.14 & 78.74 \\
\hline
\end{tabular}

Table 2 is useful information as encouragement for the manufacturer to adopt energy saving in their product. Nowadays, consumers are looking forward to saving energy in reducing their electricity bills. This preference reflects by the over $80 \%$ of the respondents are looking forward to the 'energy saving star rating' product. However, the manufacturer should concern about the price because most of the respondents are not belongs to the higher-level income group.

\section{Conclusion}

The primary objective of this paper is to focus on a preliminary study in discovering the youth lifestyle towards energy saving. The research initiated by designing an appropriate set of questionnaires. Then, the survey distributed to the targeted respondent level, youth in a selected higher-level institution. The responses recorded in an offline mode then later converted into an online version. The analysis made based on the summary of the survey results. It shows that $67.15 \%$ of the respondents are implementing energy saving in their lifestyle. This habit partially influences their preferences in choosing electrical appliances with $78.74 \%$ of the respondents are looking forward to energy saving products that come with a known brand and affordable price. 


\section{Acknowledgment}

We gratefully thank the participants of this survey, students of Universiti Tenaga Nasional and lecturers for their cooperation given in the data gathering process.

\section{References}

[1] "Malaysians spend 14 hours daily on digital devices: Survey", Nst.com.my, $2016 . \quad$ [Online]. Available: https://www.nst.com.my/news/2016/11/189176/malaysians-spend14-hours-daily-digital-devices-survey. [Accessed: 01- Jul- 2018].

[2] FOMCA, KeTTHA, Kempen kesedaran kecekapan tenaga kebangsaan (SWITCH): buku panduan tenaga (untuk pengguna).

[3] B. Holmes, "Energy: Knowledge and Attitudes, A National Assessment of Energy Awareness Among Young Adults", National Assessment of Educations Progress, Colorado, 1978.

[4] Youthpolicy.org, Malaysia | Factsheets | Youthpolicy.org (2015). [Online]. Available: http://www.youthpolicy.org/factsheets/country/malaysia/. [Accessed: 23- Nov-2015].

[5] E. Ahmed, "Factors Determining Malaysia To Be A Developed Nation", Casuarina Hotel, Ipoh, Perak Darul Ridzuan, 2015.

[6] Unit Perancang Ekonomi Jabatan Perdana Menteri, Laporan Kesejahteraan Rakyat Malaysia 2013 - EPU, EPU (2015).

[7] Department Of Statistics, Malaysia, Report On Characteristics Of Household 2010 (2010).

[8] "ICT Use and Access By Individuals and Households Survey Report, Malaysia, 2017", Dosm.gov.my, 2018. [Online]. Available: https://www.dosm.gov.my/v1/index.php?r=column/cthemeByCat\& cat=395\&bul_id=bHBzbWxkWElxRDlmaU81Q3R2ckRkZz09\&m enu_id=amVoWU54UT10a21NWmdhMjFMMWcyZz09. [Accessed: 01- Jul- 2018].

[9] Union of Concerned Scientists, Environmental Impacts of Natural Gas (2015). [Online]. Available: http://www.ucsusa.org/clean_energy/our-energy-choices/coal-andother-fossil-fuels/environmental-impacts-of-naturalgas.html\#.VmLuYN8rIn0. [Accessed: 05- Dec- 2015].

[10] TNB Better. Brighter., TNB Better. Brighter., (2015). [Online]. Available: http://www.tnb.com.my. [Accessed: 01- Dec- 2015].

[11] N. Salleh, "Youth Awareness Towards Energy Saving", Advanced Science Letters, vol. 22, no. 10, pp. 3004-3006, 2016.

[12] T. Syed Hussain, H. Ismail and M. Md Noh, "Kesedaran Mengenai Penjimatan Tenaga Elektrik dan Kelestarian Alam Sekitar", in Persidangan Kebangsaan Ekonomi Malaysia ke VIII (PERKEM VIII) - "Dasar Awam Dalam Era Transformasi Ekonomi: Cabaran dan Halatuju”, Johor Bahru, 2013, pp. 977 - 990.

[13] L. M. Given, The SAGE Encyclopedia of Qualitative Research Methods. California: SAGE Publications, Inc (2008).

[14] Vagias, Wade M. Likert-type scale response anchors. Clemson International Institute for Tourism \& Research Development, Department of Parks, Recreation and Tourism Management. Clemson University (2006)

[15] "Research: Participants, respondents, subjects - what is the difference Flashcards | Quizlet", Quizlet. [Online]. Available: https://quizlet.com/72883412/research-participants-respondentssubjects-what-is-the-difference-flash-cards/. [Accessed: 18- Aug2018].

[16] H. Barratt, "Methods of sampling from a population", Health Knowledge, 2009. [Online]. Available: https://www.healthknowledge.org.uk/public-healthtextbook/research-methods/1a-epidemiology/methods-of-samplingpopulation. [Accessed: 18- Aug- 2018].

[17] O. Momoh, "Stratified Random Sampling", Investopedia. [Online]. Available: https://www.investopedia.com/terms/stratified_random_sampling.a sp. [Accessed: 18- Aug- 2018].

[18] Khan Academy, Techniques for random sampling and avoiding bias. 2016.

[19] V. Easton and J. McColl, "Statistics Glossary - sampling", Stats.gla.ac.uk. [Online]. Available: http://www.stats.gla.ac.uk/steps/glossary/sampling.html. [Accessed: 18- Aug- 2018]. 